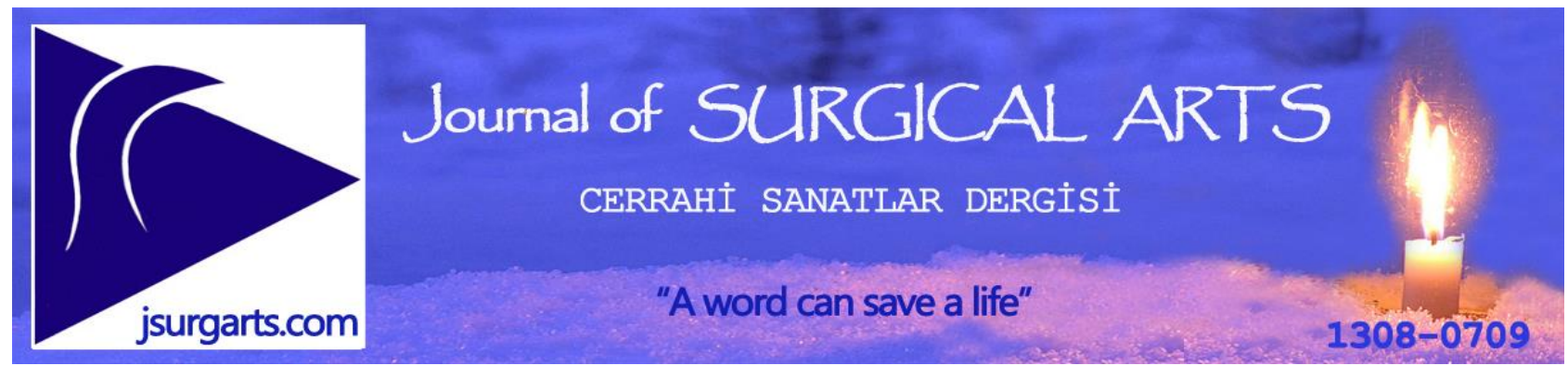

Klinik çalışma

\title{
Ultrasound assisted catheterization of internal jugular vein
}

\section{Ultrason yardımlı internal juguler ven kateterizasyonu}

\author{
Ahmet Doğan', (iD) V. Melih Kara² ${ }^{\text {iD }}$, Hacı Mehmet Odabaşı ${ }^{3}$ iD \\ Clinic Atasehir, Doktor Öğretim Üyesi ${ }^{1}$, İstanbul, Türkiye \\ Başakşehir Çam ve Sakura Şehir Hastanesi ${ }^{2}$ İstanbul, Türkiye \\ Atlas Universitesi Tıp Fakültesi, İstanbul, Türkiye \\ Address: Dr. Hacı Mehmet Odabaşı, $\quad \underline{\text { hmodabasi@gmail.com }}$ \\ How to cite: Dogan A, Kara VM, Odabasi HM. Ultrasound assisted catheterization of internal jugular vein. J Surg \\ Arts 2021;14(2):48-55. DOI: http://dx.doi.org/10.14717/jsurgarts-210201
}

Received: 08.03.2020 Accepted: 02.02.2021

\section{ABSTRACT}

An appropriate vascular access is always needed for the success of hemodialysis. Internal jugular vein is the safest and less complicated access in between central veins. At the same time, it is the most commonly used temporary vascular access for hemodialysis. The blind method after anatomical marking for the central vascular path is the most used technique in many centers. The use of ultrasound in the placement of hemodialysis catheters in the central vein increases the success rate of catheterization. Ultrasound can show IJV localization, anatomical variations, the presence of thrombus in the vein, and whether the vein is open. The aim of this study is to compare the success rate and complication frequency of temporary catheters placed in the IJV with and without ultrasound for hemodialysis.

A total of 124 consecutive patients who required hemodialysis catheters in Haydarpaşa Numune Training and Research Hospital between February 2012 and December 2012 were randomized to the study. The patients were divided into two groups as non USG-assisted (blindly) (Group 1) and ultrasound-assisted (Group 2).

The use of ultrasound significantly increased the successful catheterization rates of both experienced specialist and resident. In addition, there was no statistical difference between the success rates between the specialist and the resident.

USG-assisted vein catheterization can be performed safely, easily, quickly, more painlessly and with minimal complication rates.

Catheter intervention should be performed under the guidance of USG in risky patient groups who need temporary catheters. In centers that do not have USG, especially in such risky patients, blind catheter intervention should not be attempted after anatomical marking. USG-assisted vein catheterization can be easily performed by all clinicians and residents, since the training period is short, practical and much more safe.

Keywords: Hemodyalisis, ultrasound, venous access, catheterization.

\section{ÖZET}

Hemodiyalizin başarısı için her zaman uygun bir damar yoluna ihtiyaç vardır. İnternal juguler ven (IJV) santral venler arasında en güvenli ve az komplikasyonlu yoldur. Aynı zaman da hemodiyaliz için en sık kullanılan geçici vasküler yoldur. Birçok merkezde santral vasküler yol için anatomik işaretleme sonrası körleme (blind) yöntem en çok kullanılan tekniktir. Hemodiyaliz kateterlerinin santral vene yerleştirilmesinde ultrason kullanımı kateterizasyon başarı oranını yükseltir. Ultrason internal jügüler ven (IJV) lokalizasyonunu, anatomik varyasyonlarını, ven içinde trombus varlığını ve venin açık olup olmadığını gösterebilir. Bu çalışmanın amacı hemodiyaliz 
amacıyla İJV'e ultrason yardımlı ve yardımsız olarak yerleştirilen geçici kateterlerin başarı oranı ve komplikasyon sıklığını karşılaştırmaktır.

Şubat 2012- Aralık 2012 tarihleri arasında Haydarpaşa Numune Eğitim ve Araştırma hastanesinde hemodiyaliz kateter gereksinimi olan ardışık toplam 124 hasta randomize edilerek çalışmaya alındı Hastalar ultrasonografi (USG) yardımsız (körlemesine) (Grup 1), ultrason yardımlı (Grup 2) olmak üzere iki gruba ayrıldı.

Ultrason kullanımı hem deneyimli uzman hem de asistanın başarılı kateterizasyon oranlarını anlamlı olarak yükseltti. Ayrıca Uzman ile asistan arasındaki başarı oranları arasında istatistiksel fark saptanmadı.

USG yardımlı ven kateterizasyonu güvenli, kolay, hızlı, daha ağrısız, en az komplikasyon oranları ile gerçekleştirilebilir. Geçici kateter gereksinimi olan riskli hasta guruplarında kateter girişimi mutlaka USG kılavuzluğunda yapılmalıdır. USG'si olmayan merkezlerde özellikle bu tür riskli hastalara anatomik işaretleme sonrası körleme kateter girişimi hiç denenmemelidir. USG yardımlı ven kateterizasyonu işlemi eğitim süreci kısa, pratik ve çok daha fazla güvenli olması nedeniyle tüm klinisyenler ve asistanlar tarafından kolaylıkla yapılabilir.

Anahtar kelimeler: Hemodiyaliz, ultrason, venöz yol, kateterizasyon.

\section{GIRIȘ}

Hemodiyaliz böbrek yetmezliği, tedaviye cevap vermeyen sıvı yüklenmesi, elektrolit dengesizliği ve ciddi metabolik asidemi de endikedir. Hemodiyalizin başarısı için her zaman uygun bir damar yoluna ihtiyaç vardır (1).

Kalıcı vasküler yolu olmayan acil hemodiyaliz kararı verilmiş, hemodiyaliz kararı verilip kalıcı yolun mature olması beklenen ve kalıcı yolun çalışmadığı durumlarda hemodiyaliz için daima güvenli bir geçici yola ihtiyaç vardır. Bu amaçla sıklıkla internal juguler ven (IJJV), subclavian ven ve derin femoral venler kullanılmaktadır (2). Bunların içinde en güvenli ve komplikasyon gelişme riski diğer yollara nazaran daha az olan internal juguler vendir ve halen hemodiyaliz için en sık kullanılan geçici vasküler yoldur $(3,4)$.

Günümüzde halen birçok merkezde santral vasküler yol için anatomik işaretleme sonrası körleme (blind) yöntem en çok kullanılan tekniktir. Bu tekniğin başarı oranı ve gelişebilecek komplikasyonlar deneyimli ellerde bile değişiklik gösterebilmektedir. Özellikle obez, postürü bozuk, öncesinde IJV'e kateter girişimi yapılmış riskli hastalarda oldukça düşüktür. Hemodiyaliz kateterlerinin santral vene yerleştirilmesinde ultrason kullanımı ile IJJV lokalizasyonunu, anatomik varyasyonlarını, ven içinde trombus varlığını ve venin açık olup olmadığını gösterebildiğinden kateterizasyon başarı oranını yükseltir ve uygulama sırasında oluşabilecek komplikasyonları minimale indirir (5).

$\mathrm{Bu}$ çalışmanın amacı hemodiyaliz amacıyla İJV'e ultrason yardımlı ve yardımsız olarak yerleştirilen geçici kateterlerin başarı oranı ve komplikasyon sıklığını karşılaştırmaktır.

\section{MATERYAL ve METOD}

Şubat 2012- Aralık 2012 tarihleri arasında Haydarpaşa Numune Eğitim ve Araştırma hastanesinde hemodiyaliz kateter gereksinimi olan ardışık toplam 124 hasta randomize edilerek çalışmaya alındi. Ancak 24 hasta fizik muayene sonucunda vasküler giriş yollarının olmaması, çalışmaya katılmak istememeleri gibi nedenlerle çalışmaya alınmadılar. Çalışmaya alınan tüm hastaların bilgilendirilmiş onam formları alındı. Hemodiyaliz kateteri yerleştirmek için santral vasküler yol olarak tüm hastalarda internal juguler ven (sağ-sol) tercih edildi. Hastalar USG yardımsız (körlemesine) (Grup 1), ultrason yardımlı (Grup 2) olmak üzere iki gruba ayrıldı.

Grup 1'de anatomik işaretleme sonrası hemodiyaliz kateterleri yerleştirilirken Grup 2'de lineer problu 7,5 MHz'lik ultrason cihazı kullanılarak (HD3 Compact Ultrasound System, Philips ) her iki internal juguler ven değerlendirildi ve sonografik olarak uygun olan internal juguler vene kateter yerleştirme işlemi yapıldı. Her iki grupta da hemodializ kateterleri aseptik Seldinger tekniği ile yerleştirildi.

Körleme yöntem ile (grup 1) santral ven kateterizasyonu hemodiyaliz cerrahisi deneyiminin yanında ultrason deneyimi de olan bir cerrahi uzmanı ve körleme yöntemle santral ven kateterlerizasyonu deneyimi olan bir asistan tarafindan takıldı. USG yardımlı (grup 2) santral ven kateterizasyonu ise ultrason deneyimi olan uzman tarafından bizzat ve onun eşliğinde bir saat teorik üç saat pratik eğitimin verilmesinden sonra aynı asistan tarafindan takıldı. Pratik dersler grup 2'deki ilk 25 hasta üzerinden deneyimli uzman tarafindan verildi. Her iki grupta deneme sayısı 3 'ten fazla olması başarısızlık olarak değerlendirildi.

Boyun ve göğüs üst yarısında yaygın kollateral dolaşımı olan hastalar yüksek ihtimalle santral vasküler yolların striktüre olması nedeniyle çalışma dışı bırakıldı. Bu hastalar USG ile değerlendirildi ve geçici hemodiyaliz kateterleri için gereken vasküler yol femoral ven kullanılarak sağland.

Teknik

Tüm hastalar her iki omuz ve kulak çene hattı kapsayacak şekilde batikon ile cilt temizliğini takiben steril olarak örtüldü (Şekil 1). 


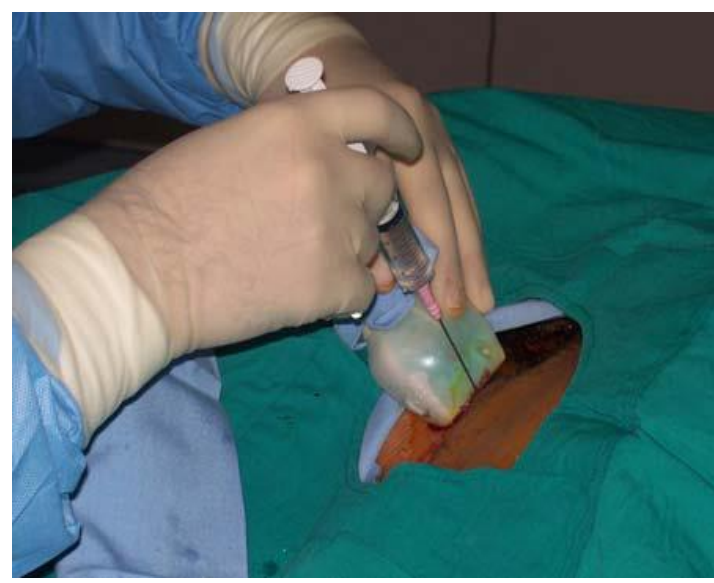

Şekil 1: Gerekli asepsi koşulları sağlandıktan sonra ultrasonografi kılavuzluğunda internal juguler vene giriş işlemi.

Grup 1'deki hastalarda kateter yerleştirilecek internal juguler ven fizik muayenede öncesinde kateter yerleştirip yerleştirilmediğine, boyunda kollateral dolaşımın olup olmadığına göre ve arterin pulsasyonunun alınabildiği ve işlemin kolay olabileceği düşünülen boyun tarafi seçildi.

Hastalar kısmen Trendelenburg pozisyonunda sırtüstü baş 45 derece açıyla aksi yöne çevrildi. Steril örtüm sonrası sternokleidomastoid kaslarının başlangıç kısımlarının oluşturduğu üçgenin apeksi belirlendi (fossa supraclavicularis minör- selldot üçgeni). Karotis arter palpe edildikten ve elin orta üç parmağ ile mediale çekildikten sonra ponksiyon yapılarak bu üçgene lokal anestezik ajan verildi. Yaklaşık 45 derece açıyla kateterin iğnesi İJV hedef alacak şekilde yavaş ve narince itildi. IJJV ponksiyonu enjektöre pulsatil olmayan koyu renkli kanın gelmesi ile anlaşıldı ve seldinger tekniği kullanılarak kateter takıldı. Karotis arterinin ponksiyonu, İJV ponksiyonu sonrası kılavuz telin ilerlemediği, işlem sırasında hastanın oksipital ya da kulak ağrısı olduğu ve enjektöre hava aspire edildiği durumlarda işlem sonlandırıldı.

Grup 2'de kateter girişimi öncesinde; hastaların her iki IJV'leri ultrason ile değerlendirilerek anatomik yapısı en uygun, içinde trombus olmayan, striktür ve kollateral gelişmemiş İJV seçildi.

Steril temizlik sonrası ultrason cihazının lineer probu klavikulanın hemen üzerinden klavikulaya paralel olacak şekilde selldot üçgenine yerleştirildi. Ultrasonda İJV daire şeklinde nonekojen, pulsatil olmamas1, kolay komprese olmas1 ve arterin superolateralinde olmasıyla teşhis edildi. Probun hemen üzerinden yaklaşık 45 derece açıyla kateterin iğnesi İJV hedef alacak şekilde yavaş ve narince itilerek kateter iğnesinin İJV lümeni içine girdiği görüldü kılavuz tel Saldinger tekniği kullanılarak IJJV içine yerleştirildi ve ultrason probuna juguler çentiğe doğru açı vererek kılavuz telin damar içinde aşağ 1 doğru ilerlediği görüldü. İJV lümeni içine itilen kılavuz telin damar içinde olası gideceği karşı taraf İJV ve her iki subklavian ven USG ile değerlendirildi.
Her iki gruptaki hastaların demografik özellikleri, venöz kateterizasyon başarı oranları, ilk girişimde başarı oranı, girişim süresi, ponksiyon sayısı (deneme sayısı 3' ten fazla olması başarısız olarak değerlendirildi), girişim sırasında ve sonrasında gelişen komplikasyonlar, hastaların işlem sırasındaki ağrıları görsel ağrı skalası (VPS) ile değerlendirildi. Bu skalada $100 \mathrm{~mm}$.'lik yatay çizgi üzerinde ve 0 'dan 10 'a kadar işaretli alan bulunmaktadır. Sıfır noktasının hiç ağrı olmadığ 1,10 noktasının dayanılmayacak şiddette ağrıyı gösterdiği anlatılarak hastaların kendi ağrı şiddetlerini işaretlemeleri istendi. Görsel ağrı skalası ile ortalama lokal anestezik tüketimi kateterizasyon başarı oranı, komplikasyon gelişimi arasındaki ilişki değerlendirildi. Grup 1' de başarısız girişim yapılan hastalar USG ile değerlendirilerek başarısızlık nedeni araştırıldı ve uygun olan IJJV'den kateterizasyonu gerçekleştirildi. Her iki gruba da girişim sonrası kateter yerini görüntülemek ve olası komplikasyonları (pnömotoraks) değerlendirmek için akciğer PA grafisi çekildi.

\section{İstatistiksel analiz}

Toplanan verilerin istatistiksel değerlendirilmesinde Chi kare, Bivariate Correlate test ve Student t-test kullanıldı. İstatistik testleri SPSS V 10. 0 paket program ile yapıld 1 ve $\mathrm{P}<0.05$ anlamlı kabul edildi.

\section{SONUÇLAR}

Çalışmaya alınan hastaların yapılan vasküler muayenelerinde; boyun ve göğüs üst yarısında yaygın cilt altı kollateral dolaşımı olan 20 hasta yüksek ihtimalle santral vasküler yolların striktüre olması nedeniyle çalışma dışı bırakıldı. Bu hastalar USG ile degerlendirildiğinde boyunda santral venlerin çapının kateter takılamayacak kadar daraldığ 1 , her iki tiroid lobunun lateralinde fazla sayıda venöz yapının belirginleştiği saptandı. Bu hastalarda hemodiyaliz için anatomik olarak yeterli vasküler akımın ve yolun olmaması nedeniyle İJV kateterizasyon işlemi yapılmadı. Bu hastaların 16'sına geçici hemodiyaliz kateterleri için gereken vasküler yol femoral ven kullanılarak sağlandı. Geriye kalan dört hastada hemodiyaliz için gerekli santral ven bulunamaması nedeniyle periton diyalizine alındı. Çalışma dışı bırakılan hastaların anamnezlerinde bize başvurularından önce her iki İJV ve subklavian venlere birden fazla kateter (kalıcı ve geçici hemodiyaliz kateteri) girişimi olduğu ortalama kateter kalış sürelerinin 2,3 $\pm 0,2$ ay olduğu saptandi.

Onam formunu imzalamayan 4 hasta çalışma dışı bırakıldı. Buna karşılık boyun ve/veya gögüs üst yarısının tek taraflı subkutan kollateral dolaŞımı olan hastalar çalışmaya dahil edildi. Geriye kalan toplam 100 hasta çalışmaya alındı. Her iki grupta 50 hasta vard1. Erkek/kadın oranı $57 / 43$, ortalama yaş 47,4 $\pm 16,7$ (r: 25 - 72). Hastaların hepsi kronik böbrek yetersizliği tanısı almış ve \%28'i diyabetikti. Öncesinde İJV'e kateter girişimi yapılmış hasta sayısı 
44'idi (Grup1'de 18, Grup 2'de 26 hasta). Tüm hastalarda tromboz ve komplikasyon riski daha düşük ve diyaliz akımına uygun olan sağ internal juguler ven kateterizasyonu ilk planda tercih edildi. Fakat hastaların fiziksel değerlendirilmesi sonrasında kateter takılacak İJV'e karar verildi. Grup 1'de kateter girişimi için daha önce kateter takılmış hastalarda kateter uygulanmamış taraf seçildi. Hastaların 32 'inde sağ 18'inde sol İJV'den kateter girişimi uygulanırken
Grup 2' de 35 hastaya sağ, 15 hastaya sol İJV' kateter girişimi uygulandı. Grupların demografik özellikleri Tablo 1'de gösterilmektedir.

Grupların demografik özellikleri değerlendirildiğinde istatistiksel olarak fark saptanmadı ve karşılaştırılabilir gruplar olduğuna karar verildi. Grupların kateter işlemi sonrası başarı oranları Tablo 2'de verilmiştir.

Tablo 1: Her iki grupta yer alan hastaların demografik özellikleri

\begin{tabular}{|l|c|c|c|}
\hline & Grup 1 (n:50) & Grup 2 (n: 50) & $\boldsymbol{P}$ \\
\hline Yaş (yıl) & $49,7 \pm 1,2$ & $51,1 \pm 1,3$ & NS \\
\hline K/E & $27 / 23$ & $32 / 18$ & NS \\
\hline Diabetik & $15(\% 30)$ & $13(\% 26)$ & NS \\
\hline KOAH & 8 & 11 & NS \\
\hline Konjestif kalp yetmezliği & 5 & 4 & NS \\
\hline $\begin{array}{l}\text { Öncesinde birden fazla girişim yapı1- } \\
\text { miş hasta }\end{array}$ & $18(\% 36)$ & $26(\% 52)$ & 059 \\
\hline BMI & $28,4 \pm 0,6$ & $29,3 \pm 0,3$ & NS \\
\hline Postur bozukluğu (kifoz,kısa boyun) & $11(\% 22)$ & $9(\% 18)$ & NS \\
\hline INR & $1,2 \pm 0,2$ & $1,1 \pm 0,1$ & NS \\
\hline
\end{tabular}

Not: bir hastada birden fazla özellik bir arada idi.

Tablo 2: Grup 1 ve Grup 2'de girişim sayıları ve başarı oranları

\begin{tabular}{|l|c|c|c|}
\hline & Grup 1 (n:50) & Grup 2 (n:50) & P \\
\hline İJV kateterizasyon oranı & $34(\% 68)$ & $48(\% 96)$ & $<0.01$ \\
\hline İlk girişimde başarı oranı & $17(\% 34)$ & $41(\% 82)$ & $<0.01$ \\
\hline İkinci girişimde başarı oranı & $13(\% 26)$ & $7(\% 14)$ & $\mathrm{NS}$ \\
\hline 3. girişimde başarı oranı & $4(\% 8)$ & - & $<0.01$ \\
\hline Başarısız girişim & $16(\% 32)$ & $2(\% 4)$ & 0.039 \\
\hline Ponksiyon sayısı 0rt. & $2,1 \pm 0,2$ & $1,24 \pm 0,2$ & $<0.01$ \\
\hline Girişim süresi (dak.) & $22,3 \pm 1,3$ & $12,5 \pm 0,9$ & \\
\hline
\end{tabular}

Tablodan da anlaşılacağ üzere ikinci girișim dışında bakılan tüm parametreler arasında istatistiksel olarak belirgin bir fark saptandı. İlk girişte başarı oranı Grup 2'de \%82, Grup1'de \%17 idi. USG kılavuzluğunda kateter işleminin başarısı \%96 iken körleme yöntemde bu oran \%68 olduğu görüldü. Grupların ortalama girişim süreleri ve ponksiyon sayıları karşılaştırıldığında USG kullanılan grupta işlemin daha kısa sürede ve daha az travmatik olarak başarıldığı görüldü.

Grup 1'de kateter girişimi başarısız olan 16 (\% 32) hasta USG ile değerlendirildiğinde, 11 hastaya USG eşliğinde uygun olan İJV'den kateter girişimi başarıyla gerçekleştirildi. 5 hastada önceki girişimlere bağlı olarak bilateral İJV'lerin trombus ile tıkalı olduğu ve kollateral geliştiği gözlendi. Hastalardan 4'üne USG eşliğinde femoral vene 1 hastada ise subklavian vene diyaliz kateteri yerleştirildi. Grup 1'de kateter girişimi başarısız olan 10 hastanın öncesinde her iki İJV'e bir ve birden fazla kateter girişimi vardi. Grup 2' de $2(\% 4)$ hastada k1lavuz tel ilerlemediğinden kateter girişimi başarısız olarak değerlendirildi.
Kateter işlemi sırasında asıl karşılaşılan sorunun hastalara verilmesi gereken pozisyonun yeterli ve uygun olarak verilememesi olduğu görüldü. Obezite, kifoz, kısa boyun, KOAH nedeniyle Grup 1'de 12 hastaya yeterli pozisyon verilemediğinden kateter takma işlemi sırasında zorluk yaşandı. Obez ve kısa boyunlu hastalarda özellikle anatomik olarak landmark olan karotis arterin palpasyonunda güçlük yaşand1, KOAH ve/veya kifozu olan hastalarda hafifte olsa trendelenburg pozisyonu verilemedi. Grup 2'de ise 16 hastada benzer sorunlarla karşılaşılmasına rağmen USG yardımıyla hastalara oturur pozisyonda kateter işlemi başarıyla gerçekleştirildi. Grupların hemodiyaliz kateteri girişim sonrası gelişen komplikasyonların karşılaştırılması Tablo 3'te gösterilmiştir.

Girişim sırasında grup 2'de $2(\% 4)$ hastada hemoraji/hematom oluşurken, grup 1'de 14 (\%28) hastada hemoraji/hematom, bunlardan 9' unda arter ponksiyonuna bağlı hematom gelişti. Grup 1'de vasküler komplikasyon gelişen hastalarda obezite, kifoz, kısa boyun, KOAH gibi ek yandaş sorunlar varken bu hastaların 7'sinde öncesinde kateter girişimi vardı. 
Körleme yöntem ile kateter takılan 1 hastada kateter karotis arterine takıld1. Bu hastada arter ponksiyonu ilk aşamada anlaşılamadı. Arter kanın rengi koyu venöz özellikte enjektörde pulsasyon vermeyen yap1dayd1. Girişim sonrası kontrol PA akciğer grafisi kontrolünde grup 1'de 1 hastada pnömotroraks saptandı. Bu hastada konservatif kalındı. Grupların ortalama görsel ağrı skorları ile hastalara kullanılan ortalama lokal analjezik miktarlarının karşılaştırılması Tablo 4'te gösterilmektedir.

Kateter girişimi sırasında görsel ağrı skalası grup 2'de ortalama 3,84 $\pm 0,5$ grup 1' de 7,72 $\pm 1,2$ $(\mathrm{p}<0.01)$ idi. Ortala analjezik kullanımı Grup 2'de 2,6 $\pm 0,3 \mathrm{cc}$, iken Grup 1'de 4,9 $\pm 0,8 \mathrm{cc}$ idi. Bu değerlerin istatistiksel olarak anlamlı olduğu bulundu. Ultrason kullanılan grupta daha az lokal anestezik ajan kullanarak daha ağrısız başarılı kateter girişimi yapild1.

Grup 1'de Görsel ağrı skalası (VPS) $\leq 5$ ile $>5$ üstü olan hastaların İJV kateterizasyon başarı oran1, ilk denemede başarı oranı, girişim süresi, ponksiyon sayısı, gelişen komplikasyon arasındaki ilişki Tablo 5'te verilmiştir.

Körleme yöntemle (Grup 1) kateter işlemi yapılan hastaların VPS $\leq 5$ ve $>5$ olan hastaların bakılan tüm parametreler karşılaştırıldığında görsel ağrı skoru düşük olan hastalarda kateterizasyon başarı oranının anlamlı olarak daha yüksek olduğu, girişim süresinin daha kısa, ponksiyon sayısının, komplikasyon sayısının, kullanılan lokal analjezik miktarının anlamlı olarak daha az olduğu görüldü. VPS $>5$ olan hastalarda ağrıyı azaltmak için daha fazla analjezik ajan kullanıldı ve sonuçta anatomik landmark olan yapıların (selldot üçgeni, karotis arter palpasyonu) verilen analjezikle kısmen veya tamamen kaybolmasına neden oldu. Sonuçta lokal aneljezik ajanla oluşturulan ödem kateter yerleştirilecek IJV bulunmasını güçleştirdi. Grup 2'de Görsel ağrı skalası (VPS) VPS $\leq 5$ ve $>5$ olan hastaların İJV kateterizasyon başarı oranı, ilk denemede başarı oranı, girişim süresi, ponksiyon sayısı, gelişen komplikasyon arasındaki ilişki Tablo 6'da verilmiștir.

Tablo 3: Grup 1 ve Grup 2'de görülen komplikasyonlar

\begin{tabular}{|l|c|c|c|}
\hline & Grup 1 & Grup 2 & P \\
\hline Hemoraji / hematom (n) & 14 & 2 & $<0.01$ \\
\hline Arter ponksiyonu & 9 & - & $<0.01$ \\
\hline Pnömotoraks (n) & 1 & - & \\
\hline
\end{tabular}

Tablo 4: Grupların ort. VPS ve ort. lokal analjezik miktarları.

\begin{tabular}{|l|c|c|c|}
\hline & Grup 1 & Grup 2 & P \\
\hline Ort. Görsel Ağrı Skoru (VPS) & $7,72 \pm 1,2$ & $3,84 \pm 0,5$ & 0.01 \\
\hline Ort. Analjezik Kullanımı (cc) & $4,9 \pm 0,8$ & $2,6 \pm 0,3$ & 0.01 \\
\hline
\end{tabular}

Tablo 5: Grup 1'de VPS $\leq 5$ ve $>5$ olan hastaların parametreleri

\begin{tabular}{|l|c|c|c|c|}
\hline & Grup 1 (n) & VPS 5 ve altı (n) & VPS 5 üstü (n) & P \\
\hline İJV kateterizasyon oranı & $34(\% 68)$ & $27(79,4 \%)$ & $7(\% 20,6)$ & $<0.01$ \\
\hline İlk girişimde başarı oranı & $17(\% 34)$ & $12(\% 70,5)$ & $5(\% 29,5)$ & $<0.01$ \\
\hline Girişim süresi (dak.) & $22,3 \pm 1,3$ & $16,2 \pm 1,1$ & $26,3 \pm 1,4$ & 0.062 \\
\hline Ponksiyon sayısı ort. & $2,1 \pm 0,2$ & $1,9 \pm 0,1$ & $2,5 \pm 0,2$ & $<0.01$ \\
\hline Kullanıla L.Analjezik (cc) & $4,9 \pm 0,8$ & $4,2 \pm 0,3$ & $6,9 \pm 0,6$ & $<0.05$ \\
\hline Komplikasyon (n) & 15 & 5 & 10 & \\
\hline
\end{tabular}

\begin{tabular}{|l|c|c|c|c|}
\hline Table 6: Kateterizasyon sonuçları. & Grup 2 (n) & VPS 5 ve altı (n) & VPS 5 üstü (n) & P \\
\hline & $48(\% 96)$ & $44(91,6 \%)$ & $4(\% 8,3)$ & $<0.01$ \\
\hline İJV kateterizasyon oranı & $38(\% 76)$ & $37(\% 97,3)$ & $1(\% 2,6)$ & $<0.01$ \\
\hline İlk girişimde başarı oranı & 17,5 & 16,2 & 18,3 & 0.062 \\
\hline Girişim süresi (dak.) & 1,38 & 1,20 & 2,0 & $<0.01$ \\
\hline Ponksiyon sayısı ort. & 2,6 & 2,2 & 3,9 & $<0.05$ \\
\hline Kullanıla L.Analjezik (cc) & 2 & - & 2 & \\
\hline Komplikasyon (n) & & & & \\
\hline
\end{tabular}


Görsel ağrı skalası 5 ve altı olan yada başka bir değişle işlem sırasında ağrı şikayeti az olan hastalarda İJV kateterizasyon başarısı, girişim süresi, ponksiyon sayısı kullanılan lokal anestezik miktarı istatistiksel olarak anlamlı bulundu. Ağrısı az olan hastalarda işlem daha hızlı ve daha başarılı gerçekleştirilirken benzer şekilde hızlı ve başarılı gerçekleştirilen işlemlerde daha az ağrı olduğu saptand.

Görsel ağrı skalası VPS $\leq 5$ olan tüm hastalarda başarılı kateterizasyon anlamlı olarak daha yüksek ve daha az komplikasyon görülürken gruplar arasinda grup 2'de grup 1' ye göre bu başarı daha belirgindi $(\mathrm{p}<0.01)$.

Körleme (Grup 1) yöntem ile santral ven kateterizasyonunun deneyimli uzman ile asistanlarının başarı oranları karşılaştırıldığında istatistiksel olarak fark saptanmadı. Deneyimli uzmanın başarılı kateterizasyon oranı $\% 72(\mathrm{n}=18)$, asistanların $\% 68(\mathrm{n}=17)$ idi.

Deneyimli Uzman eşliğinde uygun hasta seçimi yeterli vasküler muayene ve uygun hasta pozisyonu verilmesi ve USG ile boyun anatomisinin değerlendirilmesinin eğitiminin verilmesi sonrasında grup 2 'de başarılı kateterizasyon işlem oranları değerlendirildiğinde ultrason yardımlı grup 2'de deneyimli uzmanın başarılı kateterizasyon oranı \% 100 iken asistanların başarı oranı \%92 olarak körleme yönteme göre başarı oranı ciddi bir sıçrama gösterdi.

Ultrason kullanımı hem deneyimli uzman hem de asistanların başarılı kateterizasyon oranlarını anlamlı olarak yükseltti. Ayrıca Uzman ile asistan arasındaki başarı oranları arasında istatistiksel fark saptanmadi.

\section{TARTIŞMA}

Verimli bir hemodiyaliz için travmatize edilmemiş ve komplikasyon gelişmemiş geniș bir vasküler yola ihtiyaç vardır. Yapılan birçok çalışma da İJV kateterizasyonunun USG eşliğinde yapılmasının başarılı, güvenli, kolay ve hızlı uygulanan bir yöntem olduğunu bildirilmektedir (5-7). Klasik olarak santral ven kateterizasyonu anatomik bilgi ve vene yakın arterin palpasyonu ile sağlanmaktadır. Bu teknikle santral ven kateterizasyonu yapilavcak alandaki anatomik varyasyonlar saptanamayabilir (8) Başarılı bir girişim için çoğu merkezde bulunan sıradan, standart bir USG cihazının olması yeterlidir (9). Riskli hastalarda (öncesinde İJV'e kateter işlemi yapılmış, onkolojik, obez, postürü bozuk, kısa boyunlu) mutlaka USG ile her iki İJV değerlendirilerek venin açıklığı, trombus varlığ lerek oluşabilecek komplikasyonlar minimale indirilmelidir $(2,3,10,11)$. Unutulmamalıdır ki öncesinde kateter girişimi olan hastalarda İJV'de trombus, daralma buna bağlı kollateral gelişimi, inflamasyona sekonder yapışıklıklara bağlı olarak anatomik lokalizasyonda değişiklikler meydana gelebilir. Yapılan çalışmalarda saptanan \%15- 20 anatomik varyasyonlar- dan dolayı anatomik işaretleme ile körleme İJV kateterizasyonu güvenli bir yöntem değildir. Kateterizasyonun başarısızlığına ve daha kötüsü komplikasyon gelişmesine neden olabilir $(2,8)$. Obez, postürü bozuk olan hastalarda hastaya uygun pozisyonu vermek, selldot üçgeninin sınırlarını belirlemek ve karotis arter pulsasyonunu elle hissetmek zor olduğundan bu hastalarda körleme yöntemle kateter girişi yapılmamalıdır. Bu hastalarda USG eşliğinde kateter güvenli ve kolaylıkla uygulanabilir bir yöntemdir. Benzer çalışmalarda İJV'in körleme yöntemle kateterizasyon başarı oranı \%50- 80 iken USG eşliğinde bu oran \%85- 100 olarak raporlanmıștır $(5,10,12,13)$. İlk denemedeki başarı oranı körleme yöntemle \% 30-40 arasında iken USG ile \%80-90' lara çıkabilmektedir. Bizim çalışmamızda USG kılavuzluğunda kateter işleminin başarısı \%98 iken körleme yöntemde bu oran \%68 olduğu görüldü.

Körleme yöntemde hastaların önceki kateter girişimleri veya boyun ameliyatları sonucu oluşan yapışıklıklar venin anatomik yerleşimini bozabilir. Hastaların hipotansiyonu olması, obez olmaları, postürlerindeki zorluk, boyunda kemiklerde skolyoz, lordoz, arter pulsasyonunda zorlanmaya ve venin anatomik yerinin tespitinde zorluklara yol açar. Özellikle hipoksik KOAH olan hipotansif hastalarda körleme yöntem ile yapılan kateterizasyon sırasında karotis arter pulsasyonu alınamayarak arter ponksiyonu ve hatta kateterizasyonu yanlışlıkla yapılabilir. Bu hastalarda ponksiyonu yapılan arter kanın basıncı ve rengi ven kanının özelliklerini taşıyabilir ve ciddi komplikasyonların gelişmesine neden olabilir. Özellikle asidoz, sıv1 yüklenmesi ve KOAH olan hastalarda yanlışlıkla arter ponksiyonu yapılabileceği akılda tutulmalıdır (14).

Ultrason yardımıyla kateterin İJV içinde olup olmadığının yanı sıra kateterin gidiş yönüde değerlendirilebilir. Ultrason yardımlı kateterizasyon işlemi sirasında kılavuz telin ultrason ile takibi yapılarak arter içinde olmadığı ve İJV aşağı inerken pozisyonunun değerlendirilmesi yapılabilir ve subklavian vene (klavikula üzerinden bakılarak) kılavuz telin geçtiği görülebilir. Değerlendirme yaparken mutlaka diğer IJV de görüntülenmelidir nitekim bir hastamızda kılavuz telin aşağıya doğru ilerleyerek karşı taraf IJV'e geçtiği saptand1. Bu nedenle USG ile değerlendirilemeyen superior vena kava ve subklavian bileşkesinde oluşabilen bir darlık kılavuz telin yönünü de değiștirebilir. En azından işlem sırasında USG ile değerlendirilebilecek venlerin kılavuz tel yerleştirildikten sonra değerlendirilmesi önemlidir. Yolda oluşabilecek bir darlık veya obstrüksiyon, organize trombus kılavuz telin yönünü değiştirerek her iki subklavian venden aksiler venlere veya karşı taraf juguler vene telin geçmesine neden olabilir. Gerçi bu işlem sonrası akciğer grafisi ile görülebilir fakat Üst ekstremite venlerinin işlem sırasında henüz kılavuz tel yer- 
leştirildikten sonra USG ile değerlendirilmesi oluşabilecek komplikasyonların gelişmesini engeller $(2,3,15)$.

Büyük Britanya ve İrlanda Anestezistler Derneği 2016 yılında IJV'e santral venöz kateter yerleştirilmesinde USG' nin rutin kullanımını önermişlerdir. Bununla birlikte sınırlı bilgi olmakla birlikte tüm diğer santral kateter yerleştirilecek yerler içinde USG var ise aynı öneri yapılmaktadır (16). USG eşliğinde İJV kateterizasyonu deneyimli bir uzman eşliğinde teorik ve pratik üç saatlik bir eğitim sonrası asistanlar tarafindan rahatlıkla ve komplikasyonsuz olarak gerçekleştirilebilir. Hatta deneyimli uzman başarısını yakalayabilirler.Anatomik işaretleme sonrası körleme İJV kateterizasyonu başarısı deneyimli ellerde bile sinırlıdır $(6,14,15,17)$. Komplikasyon gelişme riski USG kullanımına göre oldukça yüksektir ve komplikasyon gelişme oranı yaklaşı $\% 28$ dir. Ponksiyon sayısının artması ile başarılı kateterizasyon arasında ters orantı vardir. Ponksiyon sayısı ve işlemin süresi arttıkça hekimin dikkati, başarılı olacağına dair inancı azalmakta beklide hırsını arttırmaktadır. Bu da hekimin performansı azalmakta başarısızlığa ve komplikasyon gelişmesine zemin hazırlamaktadır. Bu nedenle biz çalışmamızda üçten fazla girişime izin vermedik ve girişimin başarısız olduğuna karar verdik. Kateter yerleştirilmesi sırasında ultrasonun kullanımının eğitim süresinin kısalığı ve öğrenimin kolaylığı nedeniyle klinisyenlerin de bu işi kolaylıkla yapabileceği öneminin ortaya koymaktadır.

USG ile kateterizasyon sırasında hedef bölgenin sınırları küçültülerek, İJV'in anatomik lokalizasyon tam olarak belirlenir ve daha az lokal anestezik ajan ile daha ağrısız kateterizasyon yapılabilir. Körleme yöntemde İJV'nin anatomik lokalizasyonun net belirlenemediğinden aynı miktar analjezik kullanıldığında hastanın ağrı şikayeti artabilir. Bu durum hekimin daha fazla lokal anestezik ajan kullanmasına neden olur. Kullanılan lokal analjezik ajan miktarı arttıkça özellikle palpasyonda arter pulsasyonunun hissedilmesinde zorluğa bu da başarısız girişim oranında artmaya ve komplikasyon gelişmesine zemin hazırlayabilir. Ağr1 skalası yüksek olan hastalarda hekim hasta arasındaki ilişki sarsılacağından hastanın doktora ve başarılı olacağına dair inancında azalmaya neden olur. Ağrı hekiminde çalışmasını kötü yönde etkileyerek konsantrasyon azalmasına, başarısız olmasına ve hatta komplikasyon gelişmesine zemin hazırlayabilir. Önemli olan yeterli lokal analjezik ajanla ağrısız ve komplikasyonsuz İJV kateterizasyonunun başarabilmektir.

Girişim süresi ve ponksiyon sayısı arttıkça komplikasyon riski artmaktadır. Bizim çalışmamızda karotis arter ponksiyonu grup 1'de dokuz hastada gerçekleşti. Körleme yöntem ile kateterizayon yapılan ve komplikasyon gelişen 4 hasta interne edildi ve bu hastalar 48 saat takip edildi. Her iki işlemde de hastaların kateterizasyonu sonrası kateter yerinin ve oluşabilecek komplikasyonun değerlendirilmesi için PA akciğer grafisinin çekilmesi önemlidir. Kateterin yönü, yeri ve olası komplikasyonları değerlendirmek açışından bilgi edinilebilir.

USG yardımlı ven kateterizasyonu güvenli, kolay, hızlı, daha ağrısız, en az komplikasyon oranları ile gerçekleştirilebilir. Geçici kateter gereksinimi olan riskli hasta guruplarında kateter girişimi mümkünse USG kılavuzluğunda yapılmalıdır. USG'si olmayan merkezlerde özellikle bu tür riskli hastalara anatomik işaretleme sonrası körleme kateter girişiminin başarısızlık oranı yüksek olacaktır. USG yardımlı ven kateterizasyonu işlemi eğitim süreci kısa, pratik ve çok daha fazla güvenli olması nedeniyle tüm klinisyenler ve asistanlar tarafından kolaylıkla yapılabilir.

\section{KAYNAKLAR}

1. Fan PY, Schwab SJ. Hemodialysis vascular Access. In: Henrich WL ed. Principles and practise of dialysis. 1st edn. Williams \& Wilkins, Baltimore, 1994;22-37.

2. Farrell J, Gellens M Ultrasound-guided cannulation versus the landmark-guided technique for acute haemodialysis access. Nephrol Dial Transplant. 1998;13(2):522- 524.

3. Denys, B.G.; Uretsky, B.F.; Reddy, P.S. Ultrasound assisted cannulation of the internal jugular vein. A prospective comparison to the external 210 landmark-guided technique. Circulation 1993;87:1557-1562.

4. Slama M, Novara A, Safavian A, Ossart M, Safar M, Fagon JY. Improvement of internal jugular vein cannulation using an ultrasound- guided technique. Intensive Care Med 1997;23:916-919.

5. Lin BS, Kong CW, Tarng DC, Huang TP, Tang GJ. Anatomical variation of the internal jugular vein and its impact on temporary haemodialysis vascular access: an ultrasonographic survey in uraemic patients. Nephrol Dial Transplant. 1998;13(1):134-138.

6. Oguzkurt L, Tercan F, Kara G, Torun D, Kizilkilic O, Yildirim T. US-guided placement of temporary internal jugular vein catheters: immediate technical success and complications in normal and high-risk patients. Eur J Radiol. 2005;55(1):125-129.

7. Kunhahamed MO, Abraham SV, Palatty BU, Krishnan V, Rajeev PC, Gopinathan V. A Comparison of Internal Jugular Vein Cannulation by Ultrasound Guided and Anatomical Landmark Technique in Resource Limited Emergency Department Setting. J. Med. Ultrasound 2019;27(4):187-191.

8. Hoffman T, Du Plessis M, Prekupec MP, Gielecki J, Zurada A, Shane Tubbs R, Loukas M. Ultrasound-guided central venous catheterization: a review of the relevant anatomy, technique, complications, and anatomical variations. Clin Anat. 2017;30:237-250. 
9. Kumwenda MJ. Two different techniques and outcomes for insertion of long-term tunnelled haemodialysis catheters. Nephrol Dial Transplant. 1997;12(5):1013-1036.

10. Koroglu M, Demir M, Koroglu BK, Sezer MT, Akhan O, Yildiz H, Yavuz L, Baykal B, Oyar O. Percutaneousplacement of central venous catheters: comparing the anatomical landmark method with the radiologically guided technique for central venous catheterization through the internal jugular vein in emergent hemodialysis patients. Acta Radiol. 2006;47(1):43-47.

11. Jenssen C, Brkljacic B, Hocke M, Ignee A, Piscaglia F, Radzina M, Sidhu PS, Dietrich CF. EFSUMB Guidelines on Interventional Ultrasound (INVUS). Part VI-Ultrasound-Guided Vascular Interventions. Ultraschall Med. 2016;37:473476.

12. Nadig C, Leidig M, Schmiedeke T, Hoffken B: The use of ultrasound for the placement of dialysis catheters. Nephrol Dial Transplant 1998;13:978-981.
13. Brass P, Hellmich M, Kolodziej L, Schick G, Smith AF. Ultrasound guidance versus anatomical landmarks for internal jugular vein catheterization. Cochrane Database Syst Rev. 2015;1:CD006962

14. McGee DC, Gould MK. Preventing complications of central venous catheterization. N Engl J Med 2003;348:1123-1133.

15. Bansal R, Agarwal SK, Tiwari SC, Dash SC: A prospective randomized study to compare ultrasound-guided with nonultrasoundguided double lumen internal jugular catheter insertion as a temporary hemodialysis access. Ren Fail 2005;27:561564.

16. Brass P, Hellmich M, Kolodziej L, Schick G, Smith AF. Ultrasound guidance versus anatomical landmarks for internal jugular vein catheterization. Cochrane Database Syst Rev. 2015;1:CD006962

17. Schwab SJ, Beathard G. The hemodialysis catheter conundrum: Hate living with them, but can't live without them. Kidney Int 1999;56:1-17. 